\title{
Ritual Artifacts as Symbolic Habits-Maximizing Abducibility and Recovering Memory ${ }^{\dagger}$
}

\author{
Lorenzo Magnani \\ Department of Philosophy and Computational Philosophy Laboratory, University of Pavia, Pavia 27100, \\ Italy; lmagnani@unipv.it \\ † Presented at the IS4SI 2017 Summit DIGITALISATION FOR A SUSTAINABLE SOCIETY, Gothenburg, \\ Sweden, 12-16 June 2017.
}

Published: 9 June 2017

\begin{abstract}
The externalization/disembodiment of mind is a significant cognitive perspective able to unveil some basic features of abduction and creative/hypothetical thinking, its success in explaining the semiotic interplay between internal and external representations (mimetic and creative) is evident. This is also clear at the level of some intellectual issues stressed by the role of artifacts in ritual settings, in which also interesting cases of creative meaning formation are at play. Taking advantage of the concept of manipulative abduction, I will stress the role of some external artifacts (symbols in ritual tools). I contend these artifacts, and the habits they originate, can be usefully represented as memory mediators that "mediate" and make available the story of their origin and the actions related to them, which can be learned and/or re-activated when needed. This is especially patent in an anthropological perspective. Furthermore, symbolic habits-for example in psychoanalytical frameworks-can also be seen as memory mediators which maximize abducibility, because they maximize recoverability, in so far as they are the best possible expression of something not yet grasped by consciousness.
\end{abstract}

Keywords: ritual artifacts; habits; symbols; abduction; memory

The externalization/disembodiment of mind is a significant cognitive perspective able to unveil some basic features of abduction and creative/hypothetical thinking, its success in explaining the semiotic interplay between internal and external representations (mimetic and creative) is evident. This is also clear at the level of some intellectual issues stressed by the role of artifacts in ritual settings, in which also interesting cases of creative meaning formation are at play. Taking advantage of the concept of manipulative abduction, I will stress the role of some external artifacts (symbols in ritual tools). I contend these artifacts, and the habits they originate, can be usefully represented as memory mediators that "mediate" and make available the story of their origin and the actions related to them, which can be learned and/or re-activated when needed.

An example of ritual artifacts which can be considered "transformers of energy", can be seen in the behavior of some primitive people. They are formed by a process of semiotic delegation of meanings to "mimetic" external natural objects - for example in the ground, which apply energy for final practical purposes through the building of a mimetic representation. To make an example, a ritual artifact can be an analogue of female genitals, that through a reiterated dance-which becomes a habit shared by a collective-in turn mimicking the sexual act, suggests that the hole is in reality a vulva and refers to the implementation of some agriculture. The artifact makes possible and promotes the related inferential cognitive processes of the rite. Once the representations at play are externalized (representations which are endowed with psychic values), they can be picked up in a sensory way (and so learnt) by other individuals not previously involved in its construction. They can in turn manipulate and reinternalize the meanings semiotically embedded in the artifact. 
Primitive minds are not always a "natural home" for thinking to some targets (for example making agriculture): together with the cognitive externalization and the ritual artifact-and the subsequent recapitulations - certain actions can be triggered, actions that otherwise would have been impossible with only the help of the simple available "internal" resources.

The whole process actualizes an example of what I have called manipulative abduction. When created for the first time it is a creative social process, however, when meanings are subsequently picked up through the process involving the symbolic artifact and suitably reproduced, it is no longer creative and becomes a habit, at least from the collective point of view, but it can still be creative from the perspective of individuals' new cognitive achievements and learning. It is possible to infer (abduce) from the ritual artifacts the events and meanings that generated them, and thus the clear and reliable cognitive hypotheses which can in turn trigger related motor responses. They yield information about the past, being equivalent to the story they have undergone. In terms of Gibsonian affordances we can say that ritual artifacts as memory mediators - as reliable "external anchors" afford the subject in terms of energy stimuli transduced by sensorial systems, so maximizing abducibility (they maximize "recoverability") and actively providing humans with new, often unexpected, opportunities for both "psychic" and "motor" actions.

I have contended above that primitive mind is unlikely to have a natural home for complicated concepts, because such concepts do not exist in a definite way in the natural (not artificially manipulated) world. For example humans always resorted to "external" magical formalities and religious ceremonies, which can release deep emotion and cognitive forces. It is indeed necessary to "disembody" the mind, and after having built a ritual artifact through the hybrid internal/external interplay, to pick the new meanings up, once they are available over there. The only way is to extend the mind into the material/artifactual world, exploiting the external materials, tools and bodily movements which are suitably enriched through cognitive delegations, to provide semiotic anchors for finding ways of inferring that have no natural home within the mind, that is for finding ways of thinking that take humans beyond those that natural selection and cultural training could enable us to possess at a certain moment.

The activity of delegation to external objects of cognitive value through the construction of ritual artifacts is certainly semiotic in itself, the result is the emergence of new intrinsic meanings, expressed by what Jung [1] - for example-calls a symbol. It is to be recalled that in these cases ritual artifacts are the fruit of the hybridization of both internal and external constraints. First of all this result expresses the "quality" of the cognitive aspects delegated by "minds" to the external materiality, which gives birth to the ritual hybrid interplay. Second, it expresses the particular cognitive "reactions" triggered in other individuals by the ritual materiality at hand (that specific materials, the tools, the shapes made possible by the specific bodies which perform behaviors and actions, etc.).

Conflicts of Interest: The author declares no conflict of interest.

\section{References}

1. Jung, C.G. On psychic energy. In The Collected Works of C. G. Jung, 2nd ed.; Hull, R.F.C., Ed.; Princeton University Press: Princeton, NJ, USA, 1972; Volume 8, pp. 3-66.

(C) 2017 by the author. Licensee MDPI, Basel, Switzerland. This article is an open access article distributed under the terms and conditions of the Creative Commons Attribution (CC BY) license (http://creativecommons.org/licenses/by/4.0/). 